\title{
Fuse Vernacular Landscape in the Design of Urban Wetland Park
}

\author{
Qipeng Liao \\ School of Arts and Communication, China University of Geosciences (Wuhan), China \\ E-mail: qpliao@126.com
}

Received: May 18, 2011

Accepted: June 24, 2011

doi:10.5539/mas.v5n4p129

\begin{abstract}
The paper tries to indicate how vernacular landscape elements can play the role of inheriting local culture, economizing resources and elevating ecological benefit by analyzing the problems of urban wetland park construction. The vernacular landscape elements are divided into three types: natural vernacular landscape, artificial vernacular landscape, and intangible vernacular landscape. The application of these three kinds of vernacular landscape in the construction of urban wetland park is also elaborated.
\end{abstract}

Keywords: Wetland park, Vernacular land, Refinement

The wetland, praised as the kidney of the earth, offering the important ecological function and benefit, is one of the most important ecosystems on the Earth together with the sea and forest. (Wang, Lu, Tang, \&Wang, 2010). Urban wetland park is generally park that provides the ecological function and typical characteristics of wetland. Besides, its main functions are offering ecological protection, popularization of science, natural and wild delight and also relaxation. The essence of urban wetland park is using the existing or degenerating wetland in or around city to renew or rebuild the wetland ecosystem which is characterized by feature, nature and ecology. (Chen, Liu, $\mathrm{Lu}$, Feng \&Fu, 2008) The protection and development of wetland has been a hot topic of urban ecological environment construction these years. And there has been an upsurge of constructing urban wetland park in China. However, a series of problems such as homogenization of landscape and the absent of culture also appear. How to build the urban wetland park scientifically? It is of huge significance to fuse vernacular landscape in the design of urban wetland park.

\section{The existing problems of urban wetland park construction}

Among the upsurge of building urban wetland park, the design of such constructions is just copying the pattern of city park and water park. They assume that wetland park is just a park with some aquatic plant and installing some equipment to popular science etc. The mechanic copying and the superficial knowledge lead to three problems that cannot be avoided. First, the design that has not been scientifically schemed according to the local natural wetland ecosystem is in lack of regional characteristics, which make the urban wetland park all in the same way. Second, there has been a lack of scientific guide of theoretic knowledge, such as wetland ecology and landscape ecology; the park design did not construct a natural wetland ecosystem that is full of naturalness and all rich species, with a steady structure; the representativeness of wetland landscape and its naturalness of alternation are not featured. Third, the function of science popularization is less focused while its entertainment function is over emphasized. The noisy establishment of recreational activities of city park is introduced into wetland park. Thus, the particular serenity of urban wetland park is disturbed.

Facing the present problems of urban wetland park construction, many experts have contributed their opinions and suggestion. Some point that the construction features of urban wetland park should be in accordance with the whole environment. The number should be limited, the volume should be small and the sculpture and color should be localized. There is no doubt that the renewing and protection of wetland are of great importance; however the style of landscape decides its image. Therefore, it is necessary to discuss this topic. Combining the design practice, I think that the fusion of vernacular landscape can provide direction for the existing problems.

\section{Vernacular landscape and the significance of its application in urban wetland park}

\subsection{Vernacular landscape}

Vernacular landscape is defined as a combination of natural ecological structure and human characteristics, established by human's ancestors through reclaiming and planting. (Liu, 2003) It is restricted by natural environment and also influenced by human activities and strategies. Fusing the natural resources, ecological resources, landscape resources, village resources and humanistic folk resources, it is a dynamic comprehensive system which equips the function of aesthetics, ecology and economy. Vernacular landscape consists of vernacular natural landscape and vernacular humanistic landscape. (Yu, Wang, Huang, 2005) Vernacular landscape is obviously characterized by regional features which are constituted by landform, climate, hydrology, animals and plants. The beautiful scenery is a reflection of vernacular natural geographic landscape and regional characteristics. Vernacular humanistic landscape is a production of human activities basing on the natural landscape recourses. (Xu, 2001) The content is broader, which include villages, buildings, streets to name just a few, and also include life style, manners and customs, folk festival activities, religions, aesthetic standards, and 
moral views etc. The intangible elements of village life can also be applied into the creation work of landscape design. These elements rest in the daily life and sometime are timeliness. So it is not easy to discover, but they have strong expressive force and infection. Intangible vernacular landscape elements consist of every aspect of the peoples' lives. They are closely related with work and life. Thus, it can reflect the rich life scenes of people's life from another angle. For example, by researches the revolutionary deeds and historical stories would be dug out. The other way is folk customs, such as yangge dancing and dragon-boat racing.

\subsection{The significance of applying vernacular landscape into urban wetland park scheme}

Vernacular landscape elements are raw material of particular region. It is saved through innumerable years of selection and competition, whose appearance and characteristics are already used to the local environment. Therefore, it is of great significance of applying vernacular landscape to urban wetland park scheme.

\subsubsection{Inheriting the local culture}

Vernacular landscape elements originate from nature and a particular living environment. It is usually common and simple, but it is valuable enough to be considered as a kind of material and mental wealth. By adopting vernacular landscape elements, the local culture can be displayed, the local characteristics can be conserved; thus the landscape can be highlighted. (Deng 2007) Intangible vernacular landscape elements take an advantage in inheriting local culture. By discovering and refining the focal customs and culture and putting them into effect, it will be helpful to shape regional characteristics, which is of great significance.

\subsubsection{Economization of resources}

Applying vernacular landscape elements to the scheme of urban wetland park correspond with the construction of urban wetland park. What's more, vernacular landscape elements are from the scene. It is adaptable and the transport cost is low. Hence, the economic value can be leveled. Facing the energy crisis around the world, we can better using the resources by adopting vernacular landscape elements.

\subsubsection{Increase the ecological benefits}

Form the south to the north and from the east to the west, the wetlands of China are of different type. Therefore, wetland landscape is a reflection of a place's features. By emphasizing the application of vernacular landscape to urban wetland park, a region's feature can be exhibited. Meanwhile, since it is in accordance with objective rules, the ecological benefits are the best, which is helpful to maintain the place's environment.

\section{The application of vernacular landscape elements to the scheme of urban wetland park}

\subsection{The application of vernacular landscape elements}

The elements that can be applied to urban wetland park are all physical landscape elements which are the basic elements that constitute wetland park entities. Generally, they can be divided into two categories. Firstly, it is indigenous plants, mainly hygrophyte and water plant. Secondly, it is building materials, such as stone, soil and wood etc.

Indigenous plants refer to local plants. These plants are adaptable to the local environment after many years of evolution. The detailed application methods are summarized as follows. First, it is reservation. The field of urban wetland park generally has green environment foundation, or has some plant community. Status tree species are the most common local species. Reserving these species can bring great effects. For example, Hangzhou Xixi Wetland Park reserved a lot persimmon trees which become the most distinguished plant of the park. Second it is renewing and updating. Many urban wetland parks need first renew the wetland environment. One of the important steps is renewing the plant landscape. Then we should select the indigenous tree to establish major community, building both beautiful and stable wetland plant landscape.

Vernacular building materials can be applied to the physical construction of urban wetland park, such as feature wall, bridge, pavilion, streets and activity courts. The most common building materials are stone, wood and soil. They can function as the base. Adopting the local stones and wood to build the surface layer is economic and also distinguished. This is the most popular method to use vernacular materials. The other way is to build sketch landscape. By using these vernacular building materials, sketch landscape can be shaped with strong local characteristics. Take the Stone Township of Shandong as an example, the sketch landscapes are made of abandoned stones.

\subsection{The application of artificial vernacular landscape elements}

Artificial vernacular landscape elements are closely related with human's agricultural industry, which appears along with an area's social life. These elements can be considered as the relic of human activities on urban wetland park, and also landscape elements formed within a comparative bigger area. They can be transformed into sketch landscape by direct or indirect art process. Detailed methods are summarized as follows.

\subsubsection{Direct borrowing.}

The equipments and appliance produced during the agricultural production period can be applied directly to the design of urban wetland park, such as water wheel, stone mill and dams etc. These articles can form a sketch landscape of great local flavor. 


\subsubsection{Reconstruction.}

Reserve the typical buildings in the urban wetland park and transform them into service facilities or scenery spots by traditional craft.

\subsubsection{Blending.}

Basing on the basic patterns of particular artificial vernacular landscape, the new and old materials can be blended. Furthermore, traditional and modern craft can also be mixed to create sketch landscape of unique style.

\subsection{The refinement and application of intangible vernacular landscape elements}

Since Intangible vernacular landscape elements have a broad scope, they are not easy to master. The usual forms of these elements are cultural and artistic factors. These landscape elements can only be reflected by art production and then they are less mentioned. However, proper utilization of such elements can make the works more appealing.

\subsubsection{The refinement of intangible vernacular landscape elements}

Since intangible vernacular landscape elements involve many aspects. Only by collection, classification and refinement can they be used. As for urban wetland park, intangible vernacular landscape elements can foster the park's cultural atmosphere and make it more attractive. Therefore, it is worth of discussion. In practice, we generally collect the materials by visiting and literature searching, and then analyze the materials. Last but not least, useful information can be refined. The most important step is to master and discover valuable clue. The most common intangible vernacular landscape elements are customs and manners, traditional festivals and historic allusions etc.

\subsubsection{The application of intangible vernacular landscape elements}

The application of intangible vernacular landscape elements to urban wetland park is comparatively complicated. The main idea is to inherit fine culture. The main methods are as follows.

3.3.2.1 Inherit and carry on. Using the wetland landscape as a carrier to inherit and carry on folk custom activities and add vigor to wetland park tourism. For example, a city in the South of China develops dragon-boat races in wetland park.

3.3.2.2 Recover and elevate. The folk custom activities and historic allusions can be transformed into landscape figures and thus strengthen the landscape's local color. The wetland park's viewing area of one city installs a sketch landscape "Picking Red Water Chestnuts in Return" which adds humanistic flavor to the beautiful wetland landscape.

\section{Conclusion}

At present, the wetland parks in China function as protector and partially popularization of science and ecotourism. The developing extent of wetland tourism is continuously increasing from small scale and large scale. It is drawing more and more attention. Due to the complication and diversity of wetland, wetland design is consequently complex. Not to mention that wetland park construction has just begun; theory of wetland park design is in the exploration period. Hence, it needs further improvement and perfection. To solve the problems of wetland park construction, I put forward that vernacular elements can be applied to its design. However, encouraging the use of vernacular landscape elements does not mean to reject new materials and new craft, such as recycled materials. The perfection of wetland park design theory needs more people's efforts.

\section{References}

Chen, L., D.,Liu Y.,Lu Y. H.,Feng X. M., \& Fu B. J. (2008). Landscape pattern analysis in landscape ecology:current,challenges and future, Acta EcologicaSinica,28(11).

Kongjian, Yu, Zhifang, Wang \& Guoping, Huang. (2005). On vernacular landscape and its significance to modern landscape design. HuaZhong Architecture, (4):123-126.

$\mathrm{Li}, \mathrm{Xu}$. (2011). The development and protection of vernacular landscape during the process of vernacular tourism. Journal of Anhui Agricultural Sciences, 39 (9).

Lilong, Wang, Lin, Lu, Yong, Tang \& Changgen, Wang. (2010). The present status and regional distribution and classification of China's national level wetland park. Acta Ecologica Sinica, 09.

Liming, Liu. (2003). Design of vernacular landscape. Beijing :China Agricultural University Press.

Yi, Deng. (2007). Design of urban ecological park. Beijing: China Architecture \& Building Press. 